ADVERSE DRUG REACTION

\title{
Irreversible sensorineural hearing loss due to clarithromycin
}

\section{J Coulston, N Balaratnam}

Postgrad Med J 2005;81:58-59. doi: 10.1136/pgmj.2004.020412

Clarithromycin is a commonly used advanced generation macrolide. This case study reviews a case of an 81 year old woman who developed sensorineural deafness in the right ear after the start of low dose oral clarithromycin for an infective exacerbation of chronic obstructive pulmonary disease. Despite cessation of this drug after only three days, the sensorineural deafness was found to be irreversible.

Reversible sensorineural deafness secondary to macrolides has previously been described and evidence in the literature shows that a dose related phenomenon occurs. Research has indicated that transient dysfunction of the outer hair cells could be the possible mechanism.

In this case, however, the patient experienced an irreversible sensorineural deafness associated with the start of low dose oral clarithromycin. This is a side effect profile that has not previously been reported.

A n 81 year old woman was admitted to the Royal Gwent Hospital with severe shortness of breath. She had a history of chronic obstructive pulmonary disease (COPD), angina, hypertension, and a previous cerebrovascular accident. She was taking nifedipine, aspirin, quinine sulphate, ranitidine, and ursodeoxycholic acid as well as Combivent nebulisers and suffered sensitivity to penicillin.

Clinically, she was apyrexial with evidence of mild hypoxia on arterial sampling (partial pressure of oxygen $6.81 \mathrm{kPa}$ with saturations of $84 \%$ in air). She had left basal crepitations and a diagnosis of an acute exacerbation of COPD was made. She was started on regular nebulisers, clarithromycin $500 \mathrm{mg}$ twice a day (taken orally), and prednisolone $30 \mathrm{mg}$ once daily.

On day 3 of her admission she complained of new onset deafness in her right ear. She stated that she had been deaf, in her left ear, for many years but had had no prior problems with her right. Her testimony was supported by her family who reported a subjective reduction in her hearing over the first two days of her admission, so much that they had to shout to be heard.

The patient's medication chart was reviewed and her clarithromycin was discontinued in view of the prior reported reversible hearing loss. The patient stated that this was the only new medication that she had never previously taken.

An review by the ear, nose, and throat department was sought and an audiogram was performed. This showed (fig 1) a mixed pattern of deafness on the left (possibly due to long standing otosclerosis) and a mixed hearing loss on the right.

Magnetic resonance imaging of the brain and auditory passages was performed. This revealed no abnormality on the right side and excluded the presence of an acoustic neuroma.

The patient reported only a mild subjective improvement in the hearing on the left side over the next couple of weeks and a repeat audiogram was arranged for six weeks and then again six months after exposure. This showed (fig 2) that there was a sensorineural hearing loss in the right ear.

The patient recovered from her exacerbation of COPD and was discharged home to be followed up by the ear, nose, and throat surgeons.

\section{DISCUSSION}

Clarithromycin is one of the advanced generation macrolides. It is used commonly as a broad spectrum antibiotic, often in conjunction with a penicillin type antibiotic, for community acquired pneumonia or for patients who are penicillin sensitive (as in this case). It is an erythromycin derivative with slightly greater activity than its parent compound and achieves high tissue concentrations. ${ }^{1}$

Preliminary studies on animals in the development of the drug showed it to be well tolerated with a low side effect profile. Indeed, it is better tolerated than its parent compound. Animal studies, involving rats, mice, dogs and primates, showed there to be low potential for ototoxicity. ${ }^{2}$

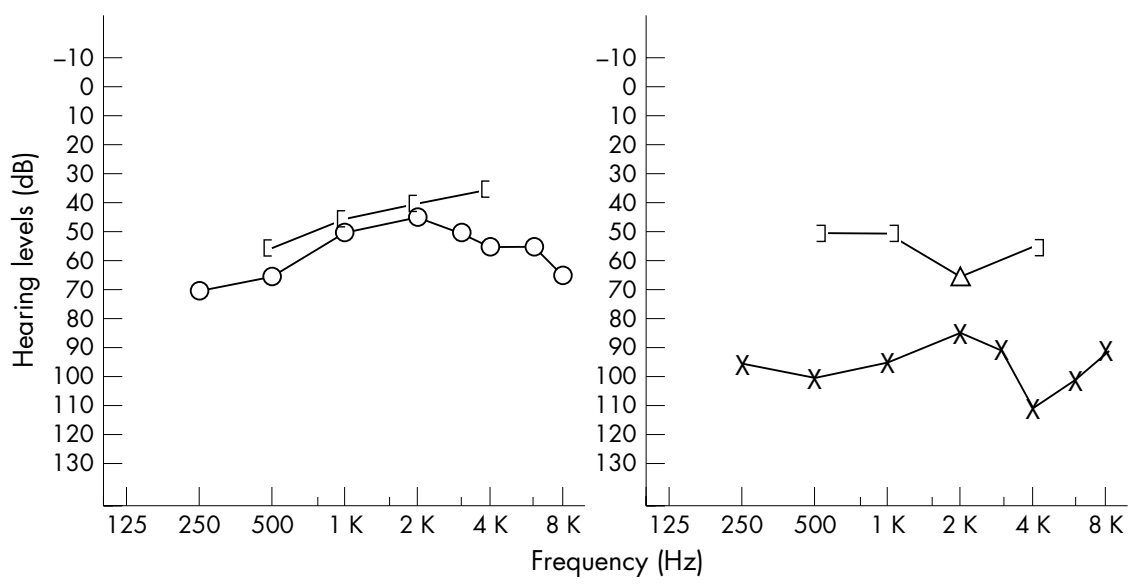

\begin{tabular}{|c|c|c|c|}
\hline HTL unmasked & $\mathrm{O}$ & & \\
\hline HTL masked & $\mathrm{O}$ & & \\
\hline $\mathrm{BCL}$ unmasked & $\triangle$ & $\triangle$ & $\triangle$ \\
\hline $\mathrm{BCL}$ masked & {[} & & J \\
\hline$M C L$ & $M$ & M & $M$ \\
\hline $\mathrm{UCL}$ & L & & \lrcorner \\
\hline \multirow{3}{*}{$\begin{array}{l}\text { FF unaided } \\
\text { FF-A aided }\end{array}$} & O & B & $x$ \\
\hline & (0) & $\langle B$ & $\langle x$ \\
\hline & Right & Binaural & Left \\
\hline
\end{tabular}

Figure 1 Audiogram on day 3 after exposure. 


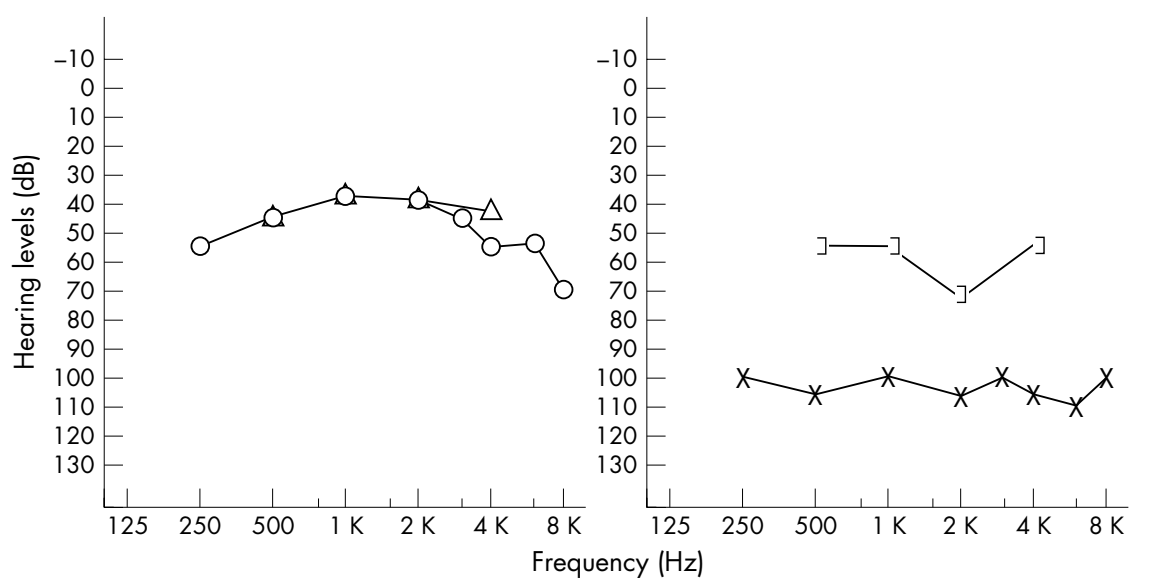

\begin{tabular}{|c|c|c|c|}
\hline HTL unmasked & 0 & & \\
\hline HTL masked & $\mathrm{O}$ & & \\
\hline $\mathrm{BCL}$ unmasked & $\triangle$ & $\triangle$ & $\triangle$ \\
\hline $\mathrm{BCL}$ masked & [ & & J \\
\hline $\mathrm{MCL}$ & $M$ & M & $M$ \\
\hline $\mathrm{UCL}$ & L & & \lrcorner \\
\hline FF unaided & O & $B$ & $x$ \\
\hline \multirow[t]{2}{*}{ FF-A aided } & (0) & BB & $\langle x\rangle$ \\
\hline & Right & Binaural & Left \\
\hline
\end{tabular}

Figure 2 Audiogram six months affer exposure.

These studies also reported that adverse reactions were not serious and usually reversible. The clinical potential for reversible hearing loss was investigated in guinea pigs by Uzun et al. ${ }^{4}$ They revealed that both clarithromycin and azithromycin had a reversible ototoxic effect at high dose.

Along with clarithromycin, erythromycin (the parent macrolide) has been investigated for ototoxicity. This was originally reported back in 1972 with two cases of reversible deafness. ${ }^{5}$ Brummett reviewed 13 cases of erythromycin ototoxicity reported over 21 years, and he concluded that there is the possibility of mainly reversible sensorineural deafness and this was dose related. ${ }^{6}$ He went on to investigate clarithromycin and stated that of the time of writing there were no reports of sensorineural deafness and that only time would tell. Azithromycin has been reported to rarely produce sensorineural hearing loss occurring at higher doses. This again is reversible on withdrawal of the drug. However, a recent case report has illustrated a case of irreversible hearing loss as a result of low dose azithromycin use. ${ }^{7}$

The work of Uzun et al with guinea pigs suggested that high doses of macrolides could cause transient dysfunction of the outer hair cells and hence transient sensorineural deafness. ${ }^{4}$ They go on to state that only in "very rare cases has the ototoxic effect of erythromycin has been reported to be irreversible"

Interestingly, in cases of macrolide induced deafness, the deafness occurs around the frequencies used for everyday speech, hence making it easier for patients to detect changes in hearing.

Looking specifically at clarithromycin, a review of the literature reveals only one reported case of ototoxicity in humans. This case occurred in the Netherlands in 2002, and the male patient was started on high dose clarithromycin for atypical pulmonary tuberculosis. ${ }^{8}$ He developed reversible sensorineural deafness. The authors went on to demonstrate the reversibility of further re-exposure and also demonstrated a dose related response.

The case, therefore, illustrates a different side effect profile not previously seen: that of irreversible sensorineural deafness associated with low dose clarithromycin use.

\section{Authors' affiliations}

J Coulston, N Balaratnam, Royal Gwent Hospital, Newport, Wales, UK

Correspondence to: Dr James Coulston, Royal Gwent Hospital, Cardiff Road, Newport NP20 2UB, UK; jamescoulston@hotmail.com

Submitted 12 February 2004

Accepted 14 April 2004

\section{REFERENCES}

1 British Medical Association and Royal Pharmaceutical Society of Great Britain. British national formulary. London: BMA and Royal Pharmaceutical Society of Great Britain, January 2003.

2 Guay DR, Patterson DR, Seipman N, et al. Overview of tolerability profile of clarithromycin in preclinical and clinical trials. Drug Safety 1993;8:350-64.

3 McConnell SA, Amsden GW. Review and comparison of advanced generation macrolides clarithromycin and dirithromycin. Pharmacotherapy 1999; 19:404-15

4 Uzun C, Koten M, Kemal M, et al. Reversible ototoxic effect of azithromycin and clarithromycin on transiently evoked otoacoustic emissions in guinea pigs. $J$ Laryngol Otol 2001; 115:622-8.

5 Mintz U, Amir J, Pinkhas J, et al. Transient perceptive deafness due to erythromycin lactobionate. JAMA 1973;255:1122-3.

6 Brummett R. Ototoxic liability of erythromycin and analogues. Otolaryngol Clin North Am 1993;5:811-9.

7 Ress B, Gross E. Irreversible sensorineural hearing loss as a result of azithromycin ototoxicity. Ann Otol Rhinol Laryngol 2000;109:435-7.

8 Kolkman W, Groeneveld JH, Baur HJ. Ototoxicity induced by clarithromycin. Ned Tiidschr Geneeskd 2002;146:1743-5. 